\title{
La conformación y las luchas por el poder en las Huastecas, 1821-1853*
}

Antonio Escobar Ohmstede

CIESAS-DF

\begin{abstract}
Se analiza el proceso de conformación de los ayuntamientos en las Huastecas, así como la forma en que estos intermediarios político-administrativos fueron

focos de conflicto entre la elite de la Huasteca. En esa región diversas facciones utilizaron a su clientela política para lograr el control de los ayuntamientos.
\end{abstract}

\section{INTRODUCCIÓN}

A nalizar la temática del federalismo mexicano, desde la publicación de la Constitución de 1824 a la liberal de 1857 , no es una tarea fácil. No lo es sólo porque carezcamos de estudios sistemáticos para mostrarnos las diversas facetas y formas que existieron, sino porque sobre él ha existido una tenaz resistencia iniciada

* Una versión de este trabajo se presentó en el seminario Centralismo-Federalismo. Revalorización y nuevas interpretaciones, La Paz, Baja California, noviembre de 1993. a fines del siglo XIX, de considerar al federalismo mexicano como una simple imitación de los Estados Unidos y no como una originalidad en cuanto resultado de una historia. ${ }^{1}$ La diferencia radicaba en que el gobierno federal

${ }^{1}$ Acerca de un balance de la historia política en el siglo XIX en la historiografia mexicana contemporánea, véase Vázquez, "Viejo tema", 1993. pp.621-631; Vázquez, "Dos décadas", 1987, pp. 7.9; Vázquez, "Federalismo", 1993, pp. 15.50; Carmagnani, "Federalismo", 1993, pp. 135-179, y Thomson, "Federalismo", 1995.

Acerca de la concepción positivista del periodo considerado como "jacobino", véase el libro tercero, primera parte ("La anarquia"), de Sierra, Evolución política, 1984. 
mexicano no gobernaría a ciudadanos, sino a estados. ${ }^{2}$

Los orígenes del federalismo mexicano han sido parcialmente explicados en un conjunto de estudios que se complementan; algunos de ellos han buscado sus antecedentes en el regionalismo; otros, en la tradición española. ${ }^{3}$ En este sentido, es el aspecto regional el que nos interesa resaltar, ya que a partir de la guerra insurgente hubo una serie de ajustes entre las regiones y el poder central o, como lo diría Brian Hamnett, existió una negociación entre "las elites regionales y la nacional" ${ }^{4}$ ya que los reajustes que habían tenido lugar a fines del periodo colonial tardío, y durante los años críticos del movimiento independentista, requirieron una transformación política, en la cual la creciente conciencia regional de fines del siglo XVIII dio

\section{4.}

2 Véase Vázquez, "Federalismo", 1993, p.

3 Hay autores que relacionan los origenes del federalismo con la creación de las diputaciones provinciales. Véase Benson, Diputación, 1952. Las diputaciones fueron parte del proceso constitucionalista gaditano. Lo importante a resaltar es el proceso de elección, el cual era indirecto. Las elecciones debían hacerse primero por parroquias, posteriormente por partidos $\mathrm{y}$ finalmente por provincias; de estas últimas saldrian los diputados que conformarian las diputaciones provinciales y que posteriormente elegirían a los representantes a Cortes. Las diputaciones tuvieron amplias atribuciones; debían de promover la prosperidad de las provincias y participar en su gobierno. Aunque la Constitución gaditana no les otorgó el rango de órganos representativos, fueron actores importantes en la vida política de las provincias.

Sobre las elecciones para diputaciones provinciales en la ciudąd de México, véase Guedea, "Primeras", 1991, pp. 16-28.

"Hamnett, "Factores", 1984, pp. 305-317. origen al federalismo de la década de 1820.

En términos generales, no podemos considerar que el federalismo mexicano surgiera como "algo espontá. neo" a partir de 1824, esto es, después del exilio de Iturbide, sino que sus raíces se remontan al periodo ilustrado europeo, el cual fue plasmado, en el caso de España y sus colonias, en las llamadas "reformas borbónicas" y en la Constitución española de 1812, siendo ésta un "parteaguas" tanto en el pensamiento político iberoamericano como en la historia política. ${ }^{5}$ Considero que la Constitución gaditana marcó la transición del antiguo al nuevo régimen, ya que las ideas que reflejaba (igualdad, libertad, eliminación de corporaciones, ciudadanía, etc.), así como la proliferación de ayuntamientos en lugares donde antes no existían, fueron cambiando tanto las estructuras sociopolíticas como las mentales. Los ayuntamientos constitucionales canalizaron el ejercicio de un nuevo derecho político legitimado por la Constitución, con lo cual se logró la eliminación de los cargos políticos hereditarios. De esa manera se comenzó a insistir en la práctica de la individualidad entre las personas que se votaban y las que eran electas. El proceso de individualización se jerarquizó, pues no todos tenían los mismos derechos y obligaciones. La participación política se restringió, algunos sectores sociales fueron excluidos, ya que las características legales para poder ser

${ }^{5}$ Acerca de cómo las reformas borbónicas contenían los principios del "Estado liberal burgués decimonónico", véase Pietschmann, "Protoliberalismo", 1992, pp. 305-317. 


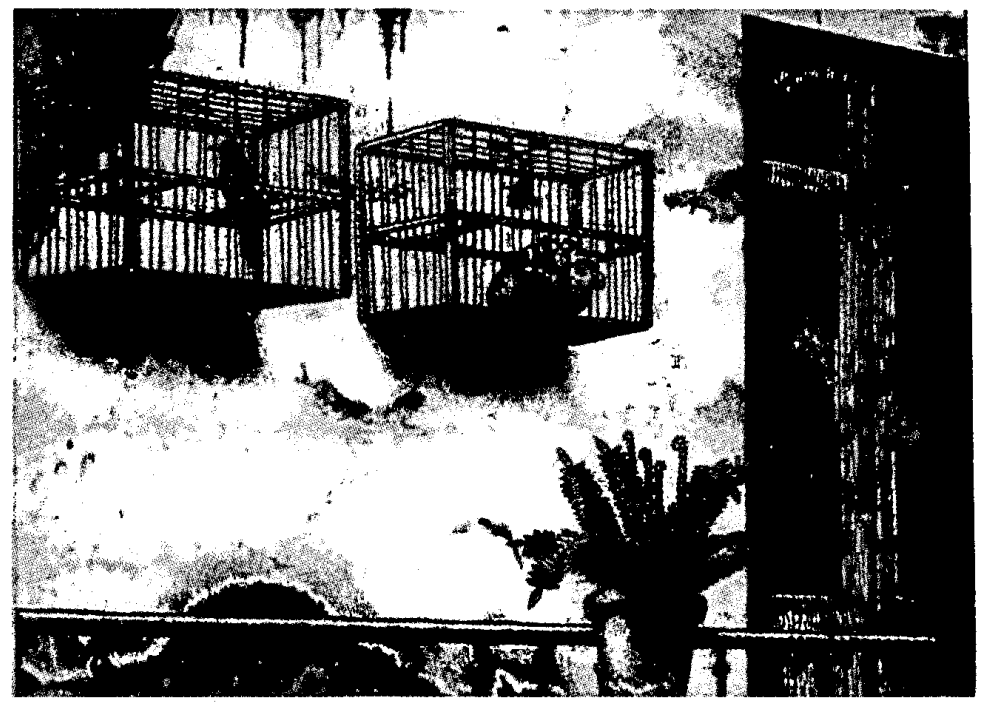

integrantes de los ayuntamientos ocasionaron que quedaran fuera los desempleados, deudores, sirvientes y quienes tuvieran juicios legales.

Así, a partir de 1812 casi todos los pueblos novohispanos eligieron ayuntamientos, lo que aumentó el número de centros urbanos que podían contar con dicha institución. ${ }^{6}$ Como parte del proceso de conformación municipal, se ha considerado que, de alguna manera, el poder político pasó del núcleo (centro) a las localidades, permitiendo que un alto número de per-

${ }^{6}$ De julio de 1820 a enero de 1821 se registraron 471 actas de conformación de ayuntamientos en Nueva España. "Lista de los ayuntamientos constitucionalistas de este reino", Archivo General de la Nación (en adelante AGN), Ayuntamientos, vol. 120. sonas se incorporaran a los procesos políticos, hecho que inició los problemas por el control del órgano políticoadministrativo. ${ }^{7}$ En este proceso no sólo se integraron sectores que habían estado relegados por el sistema político colonial, sino numerosos pueblos indios que vieron sobreponerse a su estructura político-territorial las nuevas formas de poder local. ${ }^{8}$ Este hecho de ninguna manera apartó a los indígenas para que continuaran participando como "electores" o miembros de los ayuntamientos durante el siglo XIX.

${ }^{7}$ Véase Rodríguez, "Constitución", 1991,pp. 507-536.

8 Andrés Lira ha sugerido que los ayuntamientos formados en 1812 se sobrepusieron a las comunidades de indios o bien éstas se adaptaron a la organización municipal al declarárseles 
Intentar observar cómo el federalismo se convierte en una bandera política de los sectores regionales a partir de 1821 , no podría ser explicado si no se toma en cuenta que tanto las reformas borbónicas como la Constitución gaditana y el movimiento insurgente son partes integrantes de un todo que nos puede facultar el entender la nueva conformación de fuerzas en ámbitos regionales y nacionales. ${ }^{9} \mathrm{Con}$ sidero que no se puede hablar del federalismo mexicano, y menos de sus diversas concepciones regionales, si no se plantea un estudio de larga duración, donde 1821 no sea el final o el inicio de la investigación, sino el punto intermedio, lo que nos permitiría observar las continuidades y discontinuidades durante un periodo que cubra más o menos cien años en un estudio regional.

El federalismo consignado en el pacto federal de 1824 permitió que surgiera una federación con poderes federales dotados de escasas competencias y, además, de una reducida capacidad de ejercicio, pues la parte de la soberanía que los estados concedieron -tanto de derecho como de hecho- a la federación tuvo sus raíces y límites en la colonia, periodo en el

legalmente extinguidas. Véase Lira, Comunidades, 1983, pp. 51-54. Para el caso de la Mixteca, véase Pastor, Campesinos, 1987, pp. 420-424.

${ }^{9}$ En un excelente estudio sobre el estado de San Luis Potosí, Barbara Corbett menciona cómo la oligarquía potosina abrazó el sistema federal para asegurarse el control sobre la administra. ción de las rentas más lucrativas del nuevo estado. "Fibras del poder", 1995, pp. 365-369. Sobre la Huasteca, Escobar, "Gobierno", 1996, pp. 1-26. cual las relaciones entre los diferentes actores y entre éstos y las autoridades civiles y eclesiásticas favorecieron la estructuración de fuerzas regionales permanentes. ${ }^{10}$

Así, lo que pretendemos mostrar en este trabajo es cómo los ayuntamientos se convirtieron en una nueva instancia de poder, en el cual se sustentaron los nuevos actores sociales regionales de las Huastecas (elites), siendo las instituciones locales las que van a servir de base para las reivindicaciones regionales, y donde, en más de una ocasión, van a proponer la creación de un "Estado huasteco", situación que reflejó los intereses de las elites locales por mantenerse "autónomos" de las decisiones de los poderes centrales. Hecho que no demerita el conflicto entre las elites por el control de los ayuntamientos, lucha en la cual algún grupo se ve apoyado por los pueblos indios gracias al patronaje político que desarrollaron. ${ }^{11}$

\section{I}

A partir de la independencia, algunos pueblos de las Huastecas cambiaron su fisonomía y se convirtieron en focos de atracción para la población en 15.28

${ }^{10}$ Véase Vázquez, "Federalismo", 1993, pp.

11 El patronaje político lo entendemos aquí como la relación entre dos actores sociales; está basado en el control de los recursos materiales, sociales y culturales de uno de los actores (tierras, agua, trabajo, territorio), y en una dependencia moral, que refleja en sí misma una politica de lealtad y servicio. Chubb, Patronage, 1982 , pp. $4.5,19-20$ y $144-146$. 
detrimento de otros, lo que estaba ligado a la importancia que iban tomando algunas rutas comerciales o al surgimiento de una cabecera política mucho más fuerte que las aledañas. Así tenemos, por ejemplo, que Huejutla (ubicado en la sierra Huasteca) desplazó a Yahualica como foco político y económico durante la primera mitad del siglo XIX. En 1821, ambas jurisdicciones pasaron a formar parte del estado de México, hasta que en 1869 fueron incorporadas al naciente estado de Hidalgo.

Diversas razones explican que Huejutla se transformara en un centro hegemónico en la Huasteca hidalguense. Una de éstas fue que se convirtió en paso obligado para Tampico y Tuxpan, los únicos puertos con que los huastecos contaban para sacar sus productos e ingresar otras mercancías necesarias. La importancia de Huejutla se inició con la guerra insurgente, al convertirse en un punto de defensa y control político para la zona serrana de la Huasteca. ${ }^{12}$ Este hecho provocó, posteriormente, que se le viera como un paso casi obligado, y más corto, si se provenía de Pachuca, Tulancingo o Huauchinango y el viajero o comerciante se dirigía a Tampico. En 1831 el prefecto de Huejutla, Ignacio Martínez, comentó la necesidad de reparar los caminos, ya que existian "multitud de comerciantes que de Tamaulipas, Pueblo Viejo, Tuxpan, Tampico y otros puertos están en continuo contacto con la capital federal sin poder tomar

\footnotetext{
12 Acerca del movimiento insurgente en las Huastecas, véase Escobar, "Insurgencia", 1992, pp. 133-148.
}

otro derrotero" ${ }^{13}$ Así, Huejutla pasó a controlar, en la Huasteca serrana, la ruta comercial con la ciudad de México, la cual pasaba por Pachuca, Meztitlan, Lolotla, Atotonilco, Tulancingo y se internaba en Veracruz por Tantoyuca, o en San Luis Potosí por Villa de Valles. ${ }^{14}$

La población de las Huastecas, tanto la indígena como la que no lo era, estaba dedicada a la agricultura y a la ganadería, siendo esta última muy importante debido a los hatos de ganado que pastaban en las costas y en los llanos de las Huastecas, principalmente en las propiedades privadas (haciendas y ranchos), lo que no evitaba que algunos de sus habitantes se dedicaran al comercio de piloncillo, tasajo, pieles y sal, que se dirigía a Tampico y Tuxpan. Durante toda la primera mitad del siglo XIX los habitantes del puerto tuxpeño estuvieron solicitando que éste fuera abierto como puerto de altura, ya que estaba mucho más cerca de la ciudad de México que el de Veracruz. Su apertura, se agregaba, beneficiaría al comercio de los partidos de Tulancingo y Huauchinango, así como al resto de los pueblos de la región. ${ }^{15}$

13 "Solicitando autorización para componer los caminos y puentes de la jurisdicción", Archivo Histórico del Estado de México (en adelante AHEM), c.076.62/1831/v.151/e.8.

${ }^{14}$ Acerca de los conflictos entre las elites potosinas de la Huasteca por controlar las rutas comerciales y las aduanas de Tancanhuitz y Río Verde, puntos importantes de comercio entre el altiplano de San Luis Potosí y el puerto de Tampico, véase Corbett, "Fibras del poder", 1995, pp. 384-386.

15 En 1836, cuando se cerró el puerto de Tuxpan al comercio internacional, se dijo que: 
Durante el siglo XIX algunos pueblos huastecos comenzaron a concentrar sus actividades comerciales hacia algún punto de importancia (ciudad de México, Puebla, San Luis Potosí o Tampico), lo que nos marcaría, por un lado, la relación de algunos pueblos por su actividad económica, concentrando en ellos el comercio (Huejutla, Chicontepec, Tantoyuca y Tamiahua), lo cual estaría ligado a la articulación de los productos necesarios para su mercantilización (algodón, piloncillo, pescado, sal, maíz, aguardiente y ganado).

Así tenemos que Huejutla dirigió su actividad comercial, gracias a ser un punto estrátegico de paso, hacia la ciudad de México, Atotonilco, Pachuca, San Luis Potosí y Tampico, mientras que Chicontepec y Tantoyuca lo hicieron hacia Tampico, San Luis Potosí y Puebla. Esta situación señalaría la preferencia de estos centros de acopio de productos, lo que no demeritó la existencia de otros puntos intermedios de intercambio. Podríamos considerar que las Huastecas se dividían en una serie de zonas con intereses económicos diferentes y que por tanto su interrelación variaba con base en ese interés, donde ciertas familias y gru-

\footnotetext{
"No sólo es Tuxpan el que se perjudica y arruina por la cerrada del puerto: con esa medida se ha paralizado la prosperidad de infinitos pueblos que se hallan en la sierra de Huauchinango, Zacualtipan, Papantla, Temapache, Zacatlán, Chicontepec, Tamiahua y otros muchos con Tulancingo, Teziutlán y el resto de las poblaciones comprendidas en un espacio de más trescientas leguas de terreno", Exposición de las ventajas, 1836. Véase también Soto, Nuevo estado, 1855, pp. 12-14.
}

pos manejaban el mayor volumen de mercancías.

En el caso de Huejutla, la familia Andrade controló y distribuyó la mayor parte del aguardiente, al tener el principal alambique del pueblo, producción que se consumía en los pueblos de la localidad; mientras que un excedente era comercializado en San Luis y Tampico. Además, los Andrade contaban con múltiples propiedades rurales en arrendamiento o en propiedad. En Chicontepecy Tuxpan los Llorente desarrollaban una serie de actividades que giraban tanto en la agricultura como en la ganadería. La prosperidad de los Llorente se debió al control político que llegaron a tener en el partido de Tuxpan. En la parte de Ozuluama la familia Jáuregui, gracias al acaparamiento de la tierra (eran dueños de dos de las haciendas más prósperas de la zona), fueron los más importantes en la zona de Pánuco y Tampico. Así, de una manera muy esquemática podríamos decir que tres familias controlaban los intereses económicos y políticos de las Huastecas, hecho que no evita suponer que existió una alianza entre estas familias y sectores sociopolíticos de menos importancia (pequeños propietarios, alcaldes de pueblos, indígenas, etc.). En los tres casos, miembros de las familias ocupaban puestos políticos de importancia. Los Andrade estuvieron en posesión de las jefaturas políticas y de la presidencia municipal de Huejutla, con pequeños intervalos, al menos hasta 1872. Posteriormente fueron miembros de la elite política asentada en Pachuca. Los Llorente ocuparon la comandancia militar y la jefatura política de Tuxpan 
hasta el imperio de Maximiliano, mientras que los Jáuregui fueron jueces de paz, presidentes municipales, jefes políticos de Ozuluama y diputados en el Congreso estatal de Veracruz. Así, podemos considerar que tanto el aspecto comercial como el político se concentraron en unas pocas manos. ${ }^{16}$

¿Pero qué fue lo que les permitió a estas familias controlar la vida política en las Huastecas? El considerar que la actividad económica fue lo que les dio el control político sería una parte de la verdad. Habría que pensar qué es lo que ofrecieron a una población compuesta en un $90 \%$ por indígenas, cuya actividad central era la agricultura, para que los apoyaran tanto en sus aventu-

16 Los miembros de las familias oligárquicas en las Huastecas tenían su sustento en la propiedad agrícola, que les permitía aventurarse en el comercio y la manufactura de la caña de azúcar y en el ganado. En otros casos fueron apoderados de los pueblos indios, situación que les permitía tener una clientela política que, unida a los arrendatarios y terrazgueros de sus propiedades, les dio la base política para enfrentarse entre sí en la década de los cuarenta del siglo XIX por el control de las instancias políticas locales. Por ejemplo, desde 1798 la familia Andrade y Moctezuma aparecen como vecinos de Huazalingo y algunos de sus miembros como apoderados de pueblos indios, situación que mantuvieron durante todo el siglo XIX.

La familia Llorente comenzó a tener una mayor presencia en 1819, cuando Carlos Llorente fue nombrado comandante de la segunda División de la Costa del Norte. En el transcurso de la primera mitad del siglo XIX, la familia Llorente contaba con algunos trapiches en Chicontepec, así como con varias haciendas que vendieron posteriormente a los indígenas. Algunos de sus miembros fueron jefes políticos en varias cabeceras huastecas. En el imperio de Maximiliano, la familia continuó teniendo presencia, al tener un jefe político en Tuxpan. ras bélicas como en su actividad política. Una explicación podría ser el papel de apoderados que tuvieron algunos miembros de las familias, siempre en beneficio de los pueblos indios, ya fuera en problemas de tierras o en la compra y venta de propiedades. ${ }^{17}$ Otra posibilidad es que algunos sectores de las sociedades indias participaran en el órgano de poder local, no en los puestos principales, sino como alcaldes de los pueblos y rancherías. De este modo la red de patronaje político se extendió más allá de las cabeceras políticas y de los centros económicos.

Para entender lo antes dicho es necesario observar brevemente el proceso de consolidación de los ayuntamientos durante la primera mitad del siglo XIX.

\section{II}

Como mencioné anteriormente, la Constitución gaditana permitió la proliferación de los ayuntamientos. Con base en un marco jurídico-constitucional, se definió al ayuntamiento como la forma ideal para la adminis-

17 Para la segunda mitad del siglo $\mathrm{x} 1 \mathrm{x}$ los Andrade y los Llorente fueron "accionistas" de muchos de los condueñazgos que se fueron conformando, los cuales en muchas ocasiones correspondian al territorio de los pueblos indios que se formaban en "sociedades" para poder disminuir los efectos de la ley de desamortización del 25 de junio de 1856 . Sobre los condueñazgos, véase Escobar y Schryer, "Sociedades", 1992, pp. 1-21; Escobar, "Condueñazgos", 1993, pp. 171-188, y Chenaut, Aque llos, 1995 , cap. 3. 


\section{SECUENCIA}

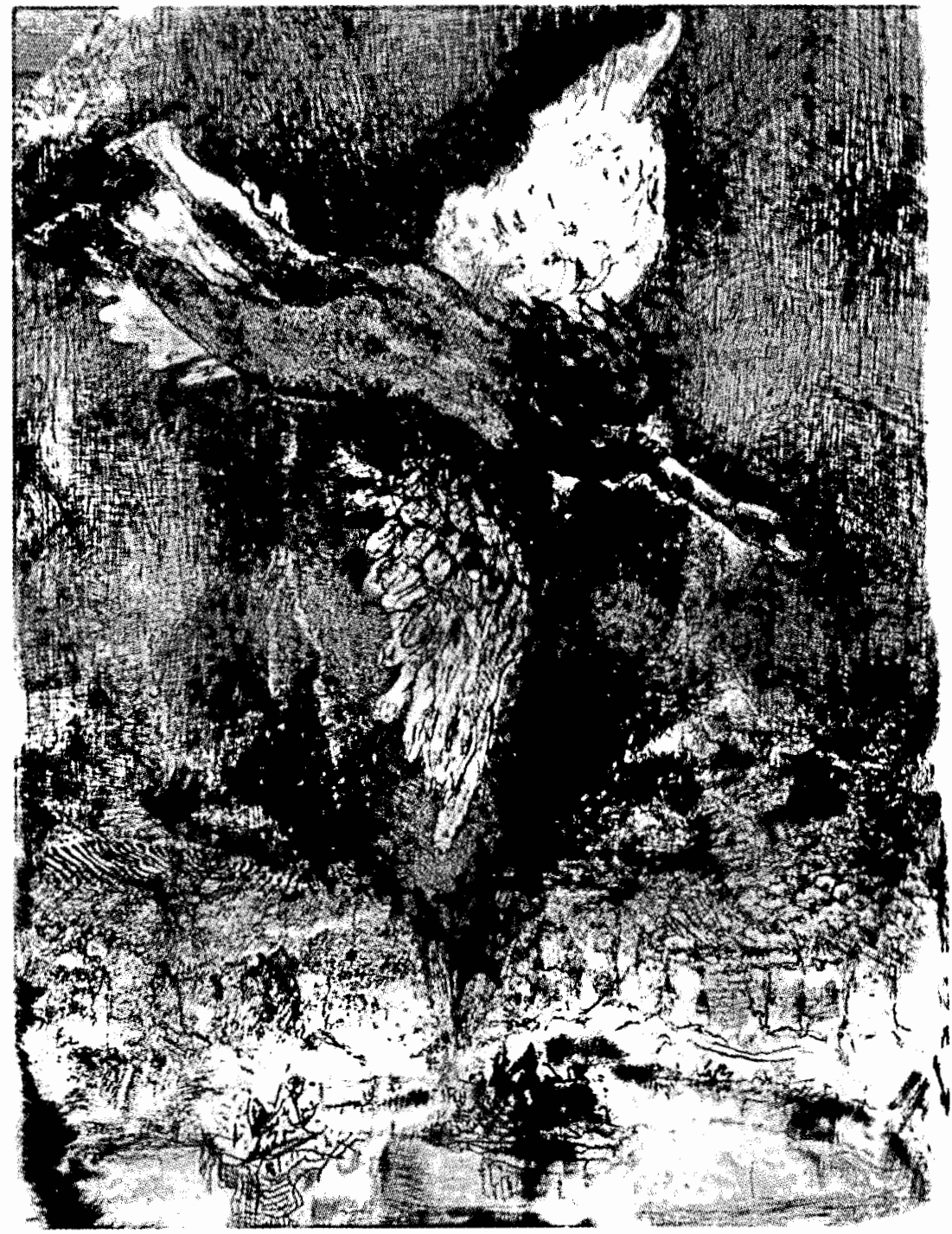


tración interna de los pueblos. ${ }^{18} \mathrm{La}$ estructura de este órgano político-administrativo estaría conformada por alcaldes, regidores y síndicos, quienes serían elegidos de manera indirecta, esto es, se debían reunir una vez al año los ciudadanos de cada pueblo para seleccionar un determinado número de electores y éstos, a su vez, a los miembros del ayuntamiento. Los ayuntamientos se crearían en los pueblos "que por sí o en su comarca lleguen a mil habitantes".

En las Huastecas el régimen municipal se puso en marcha entre agosto y septiembre de 1813, momento dificil por la existencia de grupos insurgentes en la región. Muchos de ellos no participaron en el proceso de elección; por tanto, la selección de los miembros de los ayuntamientos dependió de los sectores que apoyaban a la corona o en los pueblos controlados por tropas realistas.

Es poco lo que sabemos del ejercicio de los derechos políticos reflejados en el proceso electoral local, así como del número de electores para cada caso. La elección del ayuntamiento se dividía en dos fases. Primero se votaban electores de parroquia, los que posteriormente elegirían a los alcaldes, regidores y síndicos. ${ }^{19}$ Para la

18 "Decreto del 10 de julio de 1812. Reglas para la formación de ayuntamientos constitucionales", en Dublán y Lozano, Legislación, 1876 , vol. 1 , pp. $382-383$.

${ }^{19}$ En el caso de la renovación del Ayuntamiento de Tuxpan en 1814 se convocó al pueblo en la iglesia parroquial, eligiendo a 10 electores quienes nombraron a los miembros del Ayuntamiento. "Oficio del 5 de enero de 1814 del comandante de la segunda división del nor- elección de diputados a las Cortes y diputaciones provinciales, los comicios debían hacerse primero por parroquias, después por partidos y finalmente por provincias. ${ }^{20}$

El 17 de septiembre de 1813 el subdelegado de Huejutla informó al intendente de México de la formación de ayuntamientos, según lo mandaba la Constitución de 1812. Así, los pueblos que eligieron ayuntamientos fueron: Ixcatlan, Huejutla, PahuatlanTehuetlan, Xaltocan, Yahualica, Huazalingo, Huautla, Xochicoatlan, Santa Catarina Xochiatipan, Calnalí y Macuxtepetla, todos en la sierra Huasteca; mientras que en los llanos y en la costa fueron Tantoyuca, Tempoal, Ozuluama, Tamiahua, Tuxpan, Chiconamel, Chicontepec, Ixhuatlan, Huayacocotla e Ilamatlan. El control político-administrativo-judicial colonial, concentrado en seis cabeceras coloniales (Huejutla, Yahualica, Tantoyuca, Chicontepec-Huayacocotla, Tamiahua y Tuxpan) se diluyó en 21 ayuntamientos y posiblemente entró en un periodo de debilidad debido a la redistribución de territorios y jurisdicciones, lo que implicó una crisis de los grupos de poder local que llegaron a competir o a eliminar a las antiguas estructuras socioeconómicas de la región, ligadas a los aparatos burocráticos y comerciales del centro del país.

Algunos de los ayuntamientos de las Huastecas tuvieron una composi-

te, D. Manuel González de la Vega sobre la elección del Ayuntamiento en Tuxpan", AGN, Ayuntamiento, vol. 163.

20 Véase el caso de la ciudad de México en Guedea, "Primeras", 1991, pp. 1·28. 
ción multiétnica, esto es, incluían mulatos, indios de fuera de poblados, blancos, y mestizos, que vieron una excelente oportunidad para ocupar las antiguas redes de control indio. Otros órganos políticos administrativos estuvieron conformados por miembros de las estructuras políticas indígenas, sobre todo en aquellos pueblos que no llegaron a tener una representatividad dentro de los gobiernos indios de las cabeceras. Así, tenemos que el ayuntamiento de Huejutla con:tó entre sus catorce miembros a dos "indios principales" (ex gobernadores) y a un mulato; ${ }^{21}$ mientras que en los ayuntamientos de Ilamatlan, Huautla, Ixcatlan e Ixhuatian los miembros de las nuevas instituciones políticas eran casi todos indios (cada ayuntamiento llegó a tener entre cinco y ocho individuos), aspecto que podemos considerar por los apellidos de la gente que llegó a componer, en una primera instancia, el ayuntamiento. En los.ayuntamientos de Pahuatlan-Tehuetlan (cuya sede sería el primero), Xaltocan y Macuxtepetla los alcaldes, regidores y síndicos eran todos indigenas.

La existencia de indios en los ayuntamientos mencionados no es fortuita, yaque eran los pueblos que concentraban un mayor número de población india dentro de sus jurisdicciones, y donde los gobiernos indios tuvieron un papel sumamente fuerte en defensa de los intereses de los pueblos, tanto en el aspecto de defensa del territorio como en el jurisdiccional.

21 "Acta de elección del ayuntamiento de Huejutla del 23 de agosto de 1813", AGN, Ayuntamientos, vol. 187 .
Un aspecto que se unió a la composición racial de los ayuntamientos huastecos fue el tipo de actividad. En los conformados por no indios, el subdelegado anexó el tipo de actividad de los elegidos, mientras que en el caso de los indios sólo mencionó que eran "jornaleros". Las ocupaciones de los no indios fueron capitanes de patriotas, labradores, comerciantes, párrocos y militares de carrera, lo que muestra las características de los nuevos actores sociales; esto es, los miembros de los ayuntamientos eran personas fuertemente identificadas con la región. En las cabeceras administrativas coloniales, los componentes socioétnicos fueron preponderantemente españoles-criollos, existiendo la posibilidad de que los indígenas incorporados a los ayuntamientos-cabecera se encontraran lo suficientemente "ladinizados" para ser considerados como parte integrante del sector no indio.

Las elecciones no estuvieron exentas de problemas. Algunos sectores percibieronal ayuntamiento como una forma de controlar la vida económica y política de la región y así lograr algún tipo de provecho. Por ejemplo, el subdelegado de Huejutla informó, el 17 de septiembre de 1813, que el cura de la parroquia había manipulado las elecciones para que saliera electo alcalde un pariente político, por lo que pensaba que era necesario realizar una nueva elección. ${ }^{22}$

Con el regreso de Fernando VII al

22 "Carta del subdelegado de Huejutla Fernando de la Vega sobre problemas en la elección del Ayuntamiento, 1813", AGN, Ayuntamientos, vol. 187. 
trono español, las leyes expedidas por las Cortes fueron abolidas, y la efervescencia política originada por la apertura política tuvo que esperar hasta 1820 para expresarse. Entre 1820 y 1821 las elecciones para renovar el sistema constitucional permitieron a los pueblos volver a establecer sus ayuntamientos y que las elites locales retornaran a los puestos políticos que no volverían a soltar. Un ejemplo fue la familia Andrade, en la sierra Huasteca. Cristóbal Andrade, iniciador de la tradición familiar, ocupó a partir de 1823 importantes puestos políticos, tanto en el gobierno municipal como en el distrital, y logró gran peso político en la región. En los llanos y en la costa, las familias Llorente y Gorrochotegui fueron el ejemplo del control político en las zonas de Chicontepec-Tantoyuca y Tuxpan, al que accedieron desde sus papeles de militares y comerciantes.

De los ayuntamientos creados en 1812 sólo los de Pahuatlan-Tehuetlan, Xochicoatlan y Macuxtepetla no aparecen; pero al contrario de lo quese ha afirmado, se crearon más ayuntamientos, sobre todo en pueblos que por su número de habitantes no tenían dere. cho a contar con ayuntamiento constitucional. Este hecho se da de una manera generalizada en los llanos y en la costa, donde de los ocho ayuntamientos de 1812, el número se duplicó para 1820.23

23 Jaime E. Rodríguez O. menciona que en casi toda Nueva España se dio el proceso de erección de ayuntamientos en pueblos que no cubrían los requisitos. "La Constitución de 1824", 1991 , p. 513, nota 14.

Chevalier considera que las diputaciones provinciales autorizaron tantos municipios nue-
Lograda la independencia, y después del breve intervalo imperialista, la Constitución federal de 1824 reconoció que la organización de cada estado que compondría la federación se habria de regir con base en sus propias leyes constitucionales. ${ }^{24}$ En el caso del Estado de México, al cual pertenecía la sierra Huasteca, en 1825 se comenzó a delimitar y reglamentar el territorio que debían de constituir las municipalidades. Por medio de un decreto del 9 de febrero de 1825 , se ordenó que sólo podrían existir ayuntamientos en los pueblos en que por sí o en el territorio de su comarca tuvieran 4000 habitantes, en lugar de un ayuntamiento por cada 1000 , como había previsto la Constitución gaditana. ${ }^{25}$

Unos meses después del decreto del Estado de México, el de Veracruz publicó una ley para la "Organización, policía y gobierno interno del estado". La ley veracruzana era más laxa que la mexiquense, pues requería que los pueblos tuvieran sólo 2000 habitantes para tener ayuntamientos, ${ }^{26}$ hecho que evidencia un menor número y dis-

vos que, durante la década de 1830 , las autoridades centralistas anularon muchos de ellos. "La libertad municipal", 1989, p. 437.

${ }^{24}$ Las constituciones nacionales del siglo XIX no consagraron artículos de ordenamiento municipal, ya que se consideraba que incumbía a los estados. Hale, El liberalismo mexicano, 1978, p. 89 y Lira, "Idea", 1987, p. 51.

25 Existió una abundante discusión en el Congreso del Estado de México sobre organización municipal. Hale, El liberalismo mexicano, 1978, pp. 89-95.

26 "Ley del 26 de mayo de 1825", en Legislación del estado de Veracruz, 1881-1882, vol. I, pp. 283-294. El artículo 32 consideró la existencia de ayuntamientos en las cabeceras de can tón, no importando el número de pobladores. 
persión de población que en el Estado de México. Años después, de acuerdo con la idea centralista, Veracruz decretó una ley en la que sólo podían existir ayuntamientos en las capitales de departamento, en los pueblos que los habían tenido en 1808 y en que por sí mismos tuvieran 2000 habitantes, así como en los puertos cuya población no bajara de 4000 habitantes. ${ }^{27}$

La ley veracruzana copiaba la nacional del 20 de marzo de 1837 , que pretendía centralizar el poder local en centros políticos, con la consecuente marginación de algunos sectores regionales; asimismo intentó eliminar la autonomía de que gozaban los ayuntamientos, reduciendo su número y sus funciones. ${ }^{28}$ Por ejemplo, el prefecto de Toluca comentó que de las $25 \mathrm{mu}$ nicipalidades con que contaba su prefectura, sólo las de Toluca y Lerma podían ser consideradas para conservar el ayuntamiento. ${ }^{29}$

27 "Gobierno económico y municipal", en "Informe", Blázquez (comp.), Estado, 1986, vol. I, pp. 414-417.

El 12 de septiembre y el 12 de octubre de 1844 se publicaron dos resoluciones de la asamblea estatal veracruzana en que se autorizaba la erección de ayuntamientos que tuvieran una población de 2000 habitantes por sí y su comarca. "Informe" en Blázquez (comp.), Estado, 1986, vol. I, p. 472.

${ }_{28}$ Proceso que se encontraba enmarcado dentro de la Constitución de las Siete Leyes, que intentó crear un "Poder Conservador" que evitara lós errores de la Constitución de 1824, limitar los poderes y restringir el acceso a la vida política. Véase Sordo, "Santa Anna", 1991, vol. II, pp. 283-298.

29 "Carta del prefecto de Toluca, Luis Ma. drid, referente al artículo 177 de la ley del 20 de marzo de 1837", AHEM, c.011.2-012.1/1837-38/ v. 36/e. 10 .
Años después de la derrota del "centralismo", los ayuntamientos volvieron a recuperar su estatus de intermediarios. Para 1848 existían 175 municipios en el estado de México, aun cuando el gobernador consideraba que:

La institución es bellísima, pero en el estado casi impracticable, y el gobierno desde luego iniciaría que se limitasen estos cuerpos a las cabeceras de los partidos, si no fuera porque el artículo 159 de la Constitución del estado se opone a esa resolución. ${ }^{30}$

La vida de los ayuntamientos no fue fácil. Su existencia semiautónoma dependía de la tendencia política del país. Los "centralistas" intentaron controlarlo administrativamente creando un sistema ad hoc pero sin que los gobiernos municipales tuvieran mucha ingerencia. Por ejemplo, en la ya conocida carta-programa de gobierno que Lucas Alamán dirigió a Antonio López de Santa Anna el 23 de marzo de 1853, daba preponderancia al clero, a los co. merciantes y, en general, a los hombres de empresa, exigiendo como medida político-administrativa la desaparición de todo aquello que sonara a federación y a elecciones populares de cualquier autoridad, comenzando por las municipalidades, ya que

Chevalier menciona la marginación que sufrieron algunos pueblos que perdieron parte de su autonomía al anexarse a grandes poblaciones controladas por no indios. "La libertad municipal", 1989, p. 440.

30 Memoria de las secretarías de Relaciones y Guerra, 1849, p. 22. 
Lucas Alamán veía en ellas la causa de la falta de unidad nacional. ${ }^{31}$

Al retorno de Antonio López de Santa Anna al gobierno en 1853, se intentaron varias formas que permitieran controlar la vida de los ayuntamientos. Una de ellas fue por medio del decreto del 20 de mayo de ese año, en que se ordenó se abolieran los ayuntamientos en todos los lugares que no fueran capitales de estado, prefecturas, cantones o distritos, encargando las funciones municipales a los jueces de paz, que tenían que ser nombrados directamente por los jefes políticos. ${ }^{32}$ Un aspecto que se ligó a lo anterior fue la circular 133 del 29 de enero de 1854 , que ordenaba el envío de los inventarios de propios y arbitrios de todos los municipios, los que tendrían que mandar al tesoro nacional los sobrantes que pasaran de 5000 pesos de ingresos. ${ }^{33}$

Una ley importante fue el decreto del 17 de marzo de 1855, el cual, para atender las quejas de los pueblos indios respecto a los despojos de tierras, creó consejos municipales bajo la estrecha vigilancia de los jefes políticos, curas o vicarios. ${ }^{34} \mathrm{El}$ hecho es que para que existiera un consejo, debería haber 20 personas que supieran leer $y$

31 La carta de Alamán se encuentra en Arrangoiz, México, 1974, pp. 420-423.

32 Colin, Guía de documentos, 1977, vol. III, pp. 165-166; "Decreto de Antonio López de Santa Anna del 20 de mayo de 1853", AGN, Ayuntamientos, vol. 30 .

33 "Inventario de municipalidades de Veracruz", AGN, Ayuntamiento, vol. 59.

${ }^{34}$ Sobre el papel de los jefes políticos en la segunda mitad del siglo XIX, véase Falcón, "Jefes políticos", 1992, pp. 243-273. escribir, lo cual era prácticamente imposible, si no es que pensamos en los miembros de la oligarquía y en algunos de sus posibles aliados. Así, los pocos ayuntamientos existentes perdieron la posibilidad de atender los procesos administrativos judiciales de sus territorios.

Podemos decir que la presencia política de los ayuntamientos no sólo se observa a través de la organización administrativa del territorio, pueblos e individuos de su jurisdicción, sino también por medio de su actuación en la vida política nacional. Hasta ahora hemos encontrado en las memorias e informes de los gobernadores de los estados de México, Puebla y Veracruz menciones constantes sobre la poca funcionalidad de los municipios, ya sea por falta de fondos o por contar con gente "incompetente". Pero un hecho significativo es que el ayuntamiento, en la azarosa formación del Estado-nación mexicano, jugó un papel fundamental, ya que las diversas facciones en pugna intentaron siempre que más de un ayuntamiento apoyara sus planes políticos en contra de los gobiernos en turno. En otras ocasiones, el gobierno triunfante recibía múltiples oficios de los ayuntamientos diseminados en el país jurando su obediencia; así los municipios y sus habitantes otorgaban, forzados o no, un marco legal al "nuevo" proyecto político. ${ }^{35}$

35 Por ejemplo, en 1844 el Ayuntamiento de Huejutla y sus ciudadanos se adhirieron al régimen constitucionalista. "Oficio del 15 de diciembre de 1844 del prefecto del distrito de Huejutla, D. Cristóbal Andrade", AGN, Goberna- 
Un hecho importante es que con la pérdida del control jurisdiccional de las cabeceras indias-que fue donde se asentaron los ayuntamientos-, el proceso de conformación del ayuntamiento constitucional se vio en la imposibilidad de intervenir de manera directa en la organización de un gobierno local, a partir de un espacio definido durante la administración colonial.

Si bien la Constitución gaditana y las constituciones estatales del México independiente le otorgaron al ayuntamiento un territorio, éste no fue posible controlarlo totalmente. Ello no demerita que los ayuntamientos hayan sido vistos como un fuerte intermediario político en las Huastecas, y de allí el interés de los sectores oligárquicos por controlarlo.

\section{III}

El dominio que había tenido el Estado español sobre los diversos grupos emergentes, tanto políticos como económicos, fue roto con el triunfo de Iturbide sobre las pocas tropas fieles a la corona. La lucha de los poderes locales por intentar quedar fuera del círculo de influencia central, los empujó a abrazar el federalismo, siendo la bandera política que esgrimieron muchas de las elites provincianas. La postura de libertad y soberanía sobre territorios que mantuvieron la delimitación política colonial no satisfacía a muchos sectores oligárquicos.

ción, leg. 208, caja 301, exp. 1. Hay innumerables cartas de este tipo en el ramo Gobernación del AGN.
Los diversos intentos de crear un estado huasteco con el puerto de Tampico como capital son un ejemplo de cómo los intereses políticos se ligaron de manera intrínseca con los comerciales. No es fortuito plantear que Tampico fuera la capital del nuevo estado si tomamos en cuenta que fue la principal puerta de comercio de la intendencia de San Luis Potosí, Zacatecas y de las Huastecas en general, ${ }^{36}$ importancia que creció cuando, debido a la guerra insurgente, se buscaron nuevas rutas para extraer la plata, evitando así los caminos normales que iban a la ciudad de México, y que se encontraban infestados de insurgentes y bandidos.

Tiempo después de que Iturbide fuera elegido emperador de México surgieron los primeros intentos de crear una provincia Huasteca. En 1823 Cristóbal Andrade, presidente del ayuntamiento de Huejutla, mandó una circular a todos los ayuntamientos de Ias Huastecas potosina, veracruzana, tamaulipeca y poblana para que apoyaran y se unieran a los intereses de todos los huastecos con el fin de crear una "provincia separada de las demás" ${ }^{37}$ A esta muestra de regionalismo se opuso Villa de Valles, San Luis Potosí, pues el puerto de Tampico, introductor de efectos extranjeros, representaba una ruda competencia para el naciente comercio vallense. ${ }^{38}$ 394.

36 Véase Corbett, "Fibras", 1995, pp. 362-

37 "Acta del 17 de junio de 1823 del Ayunta. miento de Huejutla firmada por su presidente Cristóbal Andrade", AGN, Historia, caja 578-B, fs. 276r-278r.

${ }^{38}$ Márquez, "Tierra", 1986, p. 204. 


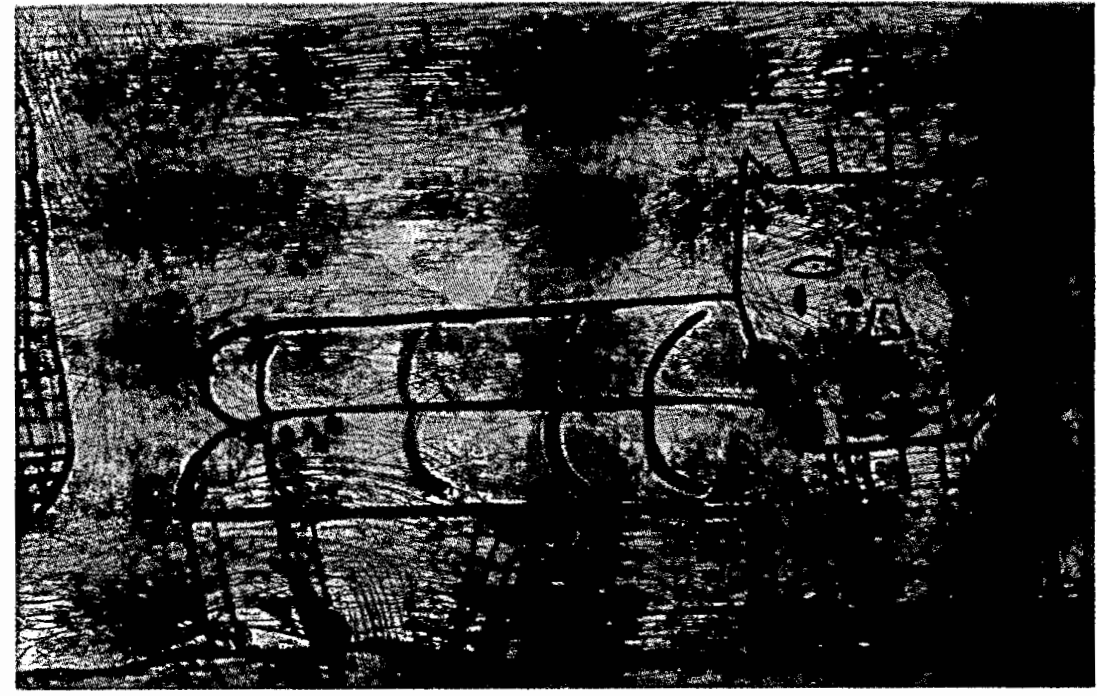

Nueve años después el general Esteban Moctezuma se levantó en contra del vicepresidente Anastasio Bustamante, secundando a la guarnición de Veracruz. En esta ocasión Moctezuma, para lograr el apoyo de importantes sectores huastecos, se pronunció por la creación de un estado Huasteco. En 1838 el general Urrea, para lograr que se le apoyara en contra del sistema centralista, les ofreció nuevamente a los huastecos erigir un estado. Diez años después, un alto militar que luchaba por controlar la "guerra de

El regionalismo puede verse como la identidad consciente, sea cultural, política o social desarrollada por un grupo de personas en ciertos espacios a través del tiempo. Véase Van Young, "Haciendo", 1991, p. 102. castas" en las Huastecas hidalguense y veracruzana afirmó que el principal interés de los sublevados era separarse y crear un estado autónomo.

Posteriores intentos, igual que los mencionados, se ligaron a conflictos entre facciones políticas, donde uno de los contrincantes ofrecía lo que parecía ser el sueño de los huastecos: conformarse en una unidad política y territorial.

En 1853 Cristóbal Andrade se pronució en Tantoyuca por la instalación del "estado de Santa Anna"; en 1855, al adherirse al Plan de Ayutla, el pueblo de Ozuluama lanzó el proyecto del “estado de Iturbide", y en 1872 con el plan de la Noria, se pidió la fundación del "estado de Moctezuma". Sin embargo, las iniciativas de autonomía po- 
lítica y unión estaban animadas por el interés económico y nutridas por las distintas y cambiantes banderas políticas nacionales, ya que en 1823 los huastecos argumentaban que "se nos indemnice de los daños y perjuicios que hasta el día nos han colocado en el abatimiento, en el desprecio y en la miseria". Sin embargo, el consenso de quienes controlaban la porción potosina nunca fue unánime. ${ }^{39}$

Los sectores huastecos tuvieron poco interés en depender directamente de los estados políticos, tal es el caso de Veracruz. Durante toda la primera mitad del siglo XIX la Huasteca veracruzana estuvo dividida políticamente en dos partes. El distrito de Tampico pertenecía al estado de Veracruz, mientras que Chicontepec y Tuxpan, al de Puebla. Esta división, herencia de las jurisdicciones coloniales, fue motivo de queja por parte de los veracruzanos. Por ejemplo, en 1831 se decía que:

El referido estado de Puebla, introduciéndose hasta la costa con sus pueblos de Tuxpan, Tamiahua y Temapache, corta la continuación del cantón [de Tampico] con el estado al que pertenece [Veracruz], reduciéndolo a un aislamiento completo que es muy perjudicial a sus intereses políticos. ${ }^{40}$

La unión del estado de Veracruz y el corte de la salida al mar que tenía

39 Véase Márquez, "Tierra", 1986, p. 203; Soto, Nuevo, 1855, pp. 4-5; "Acta de Tuxpan del 20 de diciembre de 1852", en Archivo Histórico de la Secretaría de la Defensa Nacional (en adelante AHSDN), fondo Siglo XIX, exp. XI/481.3/ 3205 , fs. 242-244.

${ }^{40}$ Estadística del Estado libre y soberano de Veracruz, 1831, p. 111.
Puebla fueron medidas tomadas por el presidente Santa Anna en 1853, con las que otorgó a sus paisanos la unión política y defraudó el sueño de los huastecos de crear un "estado Huaste$\mathrm{CO}^{\prime \prime}{ }^{41}$

\section{IV}

El incremento de los movimientos rurales regionales va ligado a las luchas políticas entre los sectores oligárquicos nacionales; muchos levantamientos llegaron a formar parte de movimientos políticos supra regionales, aspecto que no demerita la existencia de conflictos por la recuperación de la tierra perdida por los pueblos en algún momento histórico.

Es dentro de las luchas internas por la conducción de la nación y de las

41 "Decreto No. 4126 del 1 de diciembre de 1853. Se agrega el distrito de Tuxpan al departamento de Veracruz", Dublán y Lozano, Legisla. ción, 1876, vol. III, p. 797. Véase también Téllez, "Segregación", 1992, pp. 40.41

Debido al plan de Jalisco de diciembre de 1852, al que no se adhirió el gobierno poblano, Tuxpan y Chicontepec se separaron de Puebla pronunciándose por un estado huasteco; terminada la asonada los poblanos intentaron inte grar nuevamente a los pueblos huastecos en su jurisdicción, logrando una fuerte resistencia por parte de las autoridades de los pueblos, ordenando Santa Anna, como "medida conciliatoria" la unión de Tuxpan y Chicontepec a Veracruz. En 1868, el gobernador veracruzano Francisco Hernández comentó que: "La verdad es que los pueblos de la Huasteca sólo eran en el nombre partes integrantes del estado; pero real mente no sólo no tenian simpatias por él, sino que más de una vez han procurado independizarse, constituyendo una entidad politica". "Memoria", localizado èn Blázquez (comp.), Estado, 1986, t. II, p. 648. 
regiones que se desarrollaron los movimientos rurales de la primera mitad del siglo XIX en las Huastecas, manifestaciones violentas que estuvieron relacionadas con los intereses de la oligarquía regional y con sectores políticos a nivel nacional así como por conflictos regionales internos generados por el control del aparato político (ayuntamiento).

Durante la primera mitad del siglo $\mathrm{XIX}$, las Huastecas no estuvieron aisladas de los acontecimientos políticos, ni de las reivindicaciones. En algunas ocasiones (1832 y 1836-38) la región fue el centro de las demandas federalistas en contra de los gobiernos centrales, aspecto que podría ligarse al intento de las oligarquías regionales de mantener una autonomía frente al poder central.

Las Huastecas se insertaron en los conflictos nacionales en la década de 1830 , cuando el comandante militar de Río Verde (San Luis Potosí), general Esteban Moctezuma, se levantó en contra del vicepresidente Anastasio Bustamante. ${ }^{42}$ Moctezuma intentó contar con una base de apoyo regional para lograr los fines que abanderaba. Así, propuso a los grupos de poder de la región la formación de un estado huasteco.

Los nuevos intentos de crear un Estado nacional mejor cohesionado se publicaron el 25 de octubre de 1835 en las Bases Constitucionales, que convertían a los estados en departamentos cuyas autoridades quedaban

42 Sobre el desarrollo político de esta confrontación ,véase Vázquez, "Dos décadas", 1987, vol. II, pp. 14-17; Corbett, "Fibras", 1995, p. 383. sujetas al ejecutivo de la nación, restringiendo, además, el funcionamiento de los gobiernos locales (ayuntamientos) y en algunos lugares desapareciéndolos. Con el establecimiento del "centralismo", los federalistas intentaron unirse en un frente común que levantara la llama de la rebelión en México, Michoacán, Chiapas, Oaxaca y las Huastecas, pero la falta de coordinación entre los diversos sectores federales ocasionó que el levantamiento fuera rápidamente sofocado en sus inicios.

La represión de la rebelión federalista de 1836 no imposibilitó que algunos grupos aislados intentaran llevar a cabo la protesta política por medio de las armas. Los efectos se sintieron inmediatamente en las Huastecas, ya que en diciembre de 1836 los indígenas de Papantla se sublevaron encabezados por Mariano Olarte.

El movimiento olartista tuvo, en sus orígenes, reivindicaciones agrarias, políticas y jurisdiccionales que representaban las necesidades inmediatas de los indígenas. Por ejemplo, las ideas plasmadas por Olarte en su plan del 3 de diciembre de 1836 reflejaban problemas en relación con el comercio, la invasión de tierras por ganado propiedad de mestizos, el desconocimiento de las elecciones de miembros del ayuntamiento -ganadas por los indios- así como problemas ocasionados por el control del comercio de la vainilla. ${ }^{43}$ Posteriormente los rebeldes se vieron inmersos en un movimiento

43 "Peticiones de Olarte para la paz", AHSDN, fondo Siglo XIX, exp. XI/481.3/1188. Sobre la rebelión y su desarrollo, véase Chenaut, Aque. llos, 1995, pp. 100-106. 
político cuyas peticiones no reflejaban sus necesidades; así el nuevo plan proclamó un ataque al sistema de gobierno imperante, dejando en sólo dos artículos de 22, las quejas de los rebeldes. ${ }^{44}$

Durante medio año la rebelión olartista tuvo como centro la zona papantleca y la Sierra Norte de Puebla. Para mediados de 1837 los rebeldes comenzaron sus ataques en las Huastecas. Los sublevados se dirigieron al norte de Papantla, ocupando y desocupando poblaciones y propiedades particulares en las jurisdicciones de Chicontepec, Huejutla, Ixhuatlan, Tamiahua, Temapache, Tantoyuca, Tuxpan, Yahualica y Zacualtipan. La explicación de la movilidad rebelde, sobre todo abandonando una zona que conocían perfectamente y donde tenían su principal apoyo logístico (armas, hombres, comida e información), se debió a que Olarte pensó reunirse con el movimiento federalista que se aglutinaba nuevamente en torno al general Esteban Moctezuma, como lo demuestra una carta de Olarte a Moctezuma en la que el primero solicitaba recursos (dinero, armas, caballos y municiones) para sus 200 hombres, de los cuales la mitad estaban sembrando, pero que si los necesitaba los podría llamar. ${ }^{45}$

44 "Plan de Mariano Olarte del 20 de diciembre de 1836 ", AHSDN, fondo Siglo XIX, exp. XI/ 481.3/1188, fs. 239-240.

45 "Carta del 1 de agosto de 1837 de Mariano Olarte al gral. Moctezuma", AHSDN, fondo Siglo XIX, exp. XI/481.3/1256, ff. 434-435. En una sumaria que se le hizo a Pedro Guerrero, correo de Olarte, en septiembre de 1837 , comentó que eran 400 hombres y la mitad era relevada para
Mariano Olarte fúe muerto en mayo de 1838 , y a partir de ese momento el movimiento fue perdiendo fuerza hasta que el gobierno logró que todos los rebeldes fueran indultados o fusilados.

Los efectos del movimiento olartista, así como el temor de que se levantaran los indígenas de los pueblos, estuvieron latentes en las mentes de la oligarquía de las Huastecas. La división que ocasionó entre la elite la presencia de Olarte y su unión al movimiento federalista en San Luis Potosí se manifestó, principalmente, en el aspecto político. Después de la derrota de Olarte, comenzaron las denuncias contra funcionarios, hacendados y comerciantes que habían apoyado al movimiento federalista, lo que no parece fortuito si constatamos la nueva promesa de la creación de un estado huasteco. ${ }^{46}$

labores de campo. Además, agregó que Olarte había sido invitado por Paulo Verástegui y Nicolás Barragán a entrar en la "revolución". "Sumaria de septiembre de 1837", AHSDN, fondo Siglo XIX, exp. Xl/481.3/1256, fs. 456-458. Verástegui aparecerá en 1849 como el líder intelectual de la rebelión de Sierra Gorda encabezada por Eleuterio Quiroz. Dudamos que algún Barragán haya apoyado a los Verástegui, sobre todo cuando estas dos familias estaban en pugna por el control de las administraciones de rentas en la Huasteca potosina. Se considera que muchos comerciantes apoyaron el movimiento federalista de Moctezuma en junio de 1837, así como probablemente el consulado estadunidense ubicado en Tampico, que ya lo habia hecho en 1832. Véase Márquez (comp.), San Luis Potosí, 1986 , pp. 148-151. Acerca del apoyo de los Verástegui y el papel de algunos comerciantes de piloncillo en el movimiento de Moctezuma, véase Corbett, "Fibras", 1995, p. 383.

${ }^{46}$ Soto, Nuevo, 1855, p. 4. 
En marzo de 1846 se levantaron los pueblos de Amatlán, San Antonio, Tepecintla y Tancoco, del partido de Tux. pan. Las medidas conciliadoras no habian funcionado. En ese movimiento, una parte de la antigua estructura política indígena se constituyó en líder del movimiento, representada por los alcaldes de los pueblos-sujetos, quienes realizaron una recolección de dinero en 1845 y 1846 para la localización de los títulos coloniales de propiedad.

La "justicia" que pregonaron algunos miembros de la elite hacia los indígenas desapareció cuando éstos decidieron tomarla en sus manos. Tiempo después, los indígenas argumentaron que la reclamación de ciertas tierras había sido el

fundamento de la última revolución que fue indispensable hacer porque la inaudita persecución que sufríamos nos abordó hasta el desesperado extremo de tener que apelar a la fuerza fisica para salvarnos del inhumano proceder con que se nos trataba. ${ }^{47}$

Con la toma de Ozuluama por 700 indígenas y la muerte del juez de primera instancia, así como de un miembro de la prominente familia Jáuregui, se ordenó enviar 50 soldados a Ozuluama e igual número a Santa Catarina Chontla, lo que permitió el control de Tantoyuca y San Nicolás. ${ }^{48}$

47 "Representación que los vecinos de varios pueblos del estado de Veracruz dirigen al Excmo. Sr. Presidente de la República", AGN, Gobernación, caja 383 , exp. $13, \mathrm{~s} / \mathrm{s}$.

48 "Carta del 30 de mayo de 1846 del prefecto de Tampico", AHSDN, fondo Siglo XIX, exp. XI/ $481.3 / 2153$, f. 50. Posiblemente el muerto fue
A la par de la represión, se iniciaron investigaciones para averiguar las causas del levantamiento; por medio de éstas se supo que los indígenas habían ganado puestos de regidores en el Ayuntamiento de Ozuluama y exigían el respeto a las elecciones. ${ }^{49}$ Las autoridades las consideraban ilegítimas porque algunos de los indígenas electos habían participado en la recuperación de títulos de propiedad, faltando al respeto a las autoridades salientes.

El 30 de diciembre de 1847 , en los momentos más álgidos de la lucha contra el invasor norteamericano, el subprefecto del partido de Chicontepec, Juan Llorente, y el capitán de la guardia nacional de Yanhuatlán, Eduardo Herrera, proclamaron el Plan de Amatlán, que desconocía cualquier autoridad nombrada por el gobierno central, estableciendo la elección por parte del pueblo de sus representantes; prohibía todo cobro de renta de tierras, además de que éstas se declaraban comunales; igualmente sucedió

José Andrés, quien fuera oficial de milicias de la costa norte de Nueva España durante la guerra insurgente y diputado por el departamento de Tampico al Congreso de Veracruz. "Hoja de servicios del comandante José Andrés Jáuregui", AHSDN, sección de Cancelados, exp. D/III-5/3321. Se dijo que fue uno de los afectados en la rebelión, ya que los indigenas le solicitaron los títulos o escrituras de los terrenos que se litigaban.

49 En abril de 1846 el prefecto de Ozuluama comentó al ministro de Relaciones que los indigenas habian tenido tanta participación en las elecciones del Ayuntamiento que salieron regidores entre ellos. "Comunicaciones sobre la revolución en la Huasteca y complicidad de Luciano Velázquez en dicha sublevación", AGN, Gobernación, caja 342, exp. 7, s/s. ff. 70-73. Véase también Escobar, De cabeceras, cap. vIII. 
con el pago de la costumbre y obvenciones parroquiales a los curas; establecía que los pueblos de los departamentos eligieran un jefe político $\mathrm{y}$, finalmente, se declaraba la guerra al enemigo invasor. El plan reflejaba la situación del campesinado que había perdido sus tierras y pagaba renta al hacendado de San Benito. ${ }^{50}$ Un testigo de los hechos comentó varios años después:

La persuasión en que están los indígenas de que han sido despojados de la propiedad que les corresponde en estas tierras [Amatlán] y la resistencia que por consiguiente oponen al pago de los arrendamientos, han dado origen a muchas discusiones con el propietario de ellas. ${ }^{51}$

Los problemas se acentuaban en las Huastecas; el primer día de 1848 el comandante militar de Huejutla se presentó en Tantoyuca para solucionar el problema de las elecciones del Ayuntamiento. El caso era que uno de los alcaldes electos no estaba en el goce de sus derechos, según Ramón Núñez, jefe político del departamento de Tampico, quien residía en Tantoyuca. La

50 "Plan de Amatlán", AHSDN, fondo Siglo XIX, exp. XI/481.3/2772, f. 64; Reyes Heroles, Liberalismo, 1982, vol. 111, pp. 569-570; Meade, Huasteca, 1962, pp.62-63; Soto, Noticias, 1869 , p. 148. Resulta interesante que el dueño de la hacienda de San Benito fuera Juan N. Llorente, quien las vendió en abril de 1859 a los vecinos de los pueblos levantados. AGN, Nacionalización y Desamortización de Bienes, exp. 569-42/ 133.

si Fages, "Noticias", 1854, p. 265. El mismo argumento se encuentra en Soto, Noticias, 1869 , p. 148. población estaba dividida entre los que sostenían la autoridad del jefe político y el sector que pretendía llevar adelante la nueva elección, encabeza. do por Juan Llorente; este grupo era el más numeroso y contaba con el apoyo de los soldados de la guarnición. La situación empeoró cuando el comandante militar suspendió las reuniones del Ayuntamiento hasta que no se aclararan los hechos. ${ }^{52}$ Como contestación a la forma en que actuó el comandante, el grupo inconforme lanzó el Plan de Tantoyuca; éste fue promulgado bajo el mismo contexto que el de Amatlán, por problemas con el jefe político que había impugnado las elecciones en dicho pueblo.

En el caso de la rebelión de Tantoyuca y Ozuluama se consideró que Ramón Núñez, en alianza con la familia Jáuregui, pretendía controlar todos los puestos políticos del departamento, lo que ocasionaba conflictos internos en los momentos de las elecciones. ${ }^{53}$

Los planes de Amatlán y Tantoyuca fueron el resultado de la confrontación entre dos sectores de la oligarquía regional que buscaban el poder en el departamento de Tampico. Am-

52 Para suspender el goce de derechos de ciudadano se tenia que ser sirviente doméstico, ebrio, estar procesado criminalmente o por interdicción penal.

53 "Comunicaciones sobre la revolución en la Huasteca y complicidad de Luciano Velázquez en dicha sublevación", AGN, Gobernación, caja 341 , exp. 7, s/s, f. 12 r. El gobernador de Veracruz informó que la rebelión del departamento de Tampico se debía a "pretensiones de partido e intereses locales". "Informe de gobierno", localizado en Blázquez (comp.), Estado, 1986, vol. I, p. 523. 
bos grupos se definieron a sí mismos en función de sus intereses como comerciantes: el de Llorente se remontaba a finales del siglo XVIII, ${ }^{54}$ y el de Ramón Núñez a unos cuantos años antes. El problema era que Núñez centraba toda su actividad en la Huasteca potosina y el puerto de Tampico, mientras que Llorente tenía su eje en Tuxpan y Chicontepec, por lo que la presencia de Núñez en Tantoyuca obstaculizaba sus actividades de expansión.

El Plan de Tantoyuca, proclamado por Juan Llorente el 7 de enero de 1848 , invitaba a la defensa del país; declaraba que los terrenos serían comunales; prohibía el cobro de la renta a los arrendatarios anteriores y futuros; establecía que el jefe del pronunciamiento nombraría a los magistrados y empleados civiles; que se eliminarían las contribuciones directas, alcabalas, así como el estanco del tabaco y el papel sellado. La única forma de mantener las finanzas del lugar sería por medio de los impuestos que los pobladores tenían que pagar al municipio. ${ }^{55}$ Como podemos apreciar, el plan esta. ba más ligado a los intereses comerciales y políticos de los líderes que al de los campesinos que se aglutinaron a su alrededor. Aunque no dudo que el punto sobre convertir las propiedades en comunes, así como la abolición de la renta y de algunas trabas a los pro-

${ }^{51}$ La familia Llorente contaba con algunas haciendas que vendieron posteriormente a los indigenas. Algunos miembros fueron prefectos políticos de varias cabeceras huastecas (Chicontepec, Tuxpan y Temapache).

55 "Plan de Tantoyuca", AHSDN, fondo Siglo xIX, exp. XI/481.3/2772, f. 131. ductos comerciales, atrajeran a grupos considerables de campesinos, creo que el punto central del plan era el control de la maquinaria política de la región, al nombrar Llorente a las autoridades civiles, así como al proponer de nuevo la creación de un estado huasteco. 56

El discurso "nacionalista" del plan de enero de 1848 en cuanto a defender al país de los estadunidenses reflejaba la conveniencia de la elite local de proteger sus intereses ante un posible dislocamiento social provocado por la invasión, situación que estaría fuera de su control; por ello, plasmar en una proclama política la defensa del territorio, no iba en contra de las corrientes imperantes en México, lo que evitaría que fueran considerados por otros grupos políticos y económicos como antinacionalistas. El pretendido nacionalismo de la elite de las Huastecas no pudo haber sido sentido de la misma manera por los campesinos, sobre todo si el ejército norteamericano o las fuerzas mexicanas pasaban por sus casas y tierras.

Ante los hechos consumados, el comandante de la línea militar de Huejutla firmó un armisticio con Llorente para que el primero se retirara a Huejutla sin ser molestado. La rebelión se fortalecía con sublevados de Chicontepec, Ozuluama, San Nicolás y Tantoyuca, todos bajo las órdenes de Llo-

\footnotetext{
56 "Carta del 31 de enero de 1848 del comandante de Huejutla", AHSDN, fondo Siglo XIX, exp. $\mathrm{xl} / 481.3 / 2772$, fs. 70-71. La autoridad militar mencionó que los rebeldes "tratan de dar un giro a la revolución al declarar a la Huasteca, estado libre y soberano".
} 
rente. ${ }^{57}$ Es curioso que se adhirieran al acta de Tantoyuca, el 20 de enero, los habitantes de la hacienda de Cayahual, de la jurisdicción de Yahualica, en presencia del dueño de la hacienda, quien posiblemente simpatizaba con el grupo de Llorente. La adhesión fue a todos los puntos del plan, reconociéndose la autoridad de Llorente pero determinándose una salvedad: que si bien las tierras eran comunes, se marcarian mojoneras, respetándolas hasta que fueran nombradas las nuevas autoridades, según la propuesta del plan. 58

El gobierno ordenó que las milicias de San Luis, México y Veracruz atacaran a los sublevados. La desventaja de la sublevación fue que faltó una organización logística que permitiera tener un frente común; y el que cada pueblo alzado actuara de manera independiente ocasionó que, si bien el movimiento fue generalizado, la rebelión se circunscribiera a localidades específicas. Así sucedió con los ataques de los pueblos rebeldes a las cabeceras políticas de la región, identificadas en un primer momento como el centro de la injusticia.

A la par de la sublevación bajo la bandera del Plan de Tantoyuca, comenzaron a llegar informes al gobierno central de la posible unión de Ma-

57 "Carta del 12 de febrero de 1848 del prefecto de Tampico al ministro de guerra", AHSDN, fondo Siglo XIX, exp. XI/481.3/2772, f. 102. Donde se avisa la unión de Llorente con los de San Nicolás. Tanto el Plan de Amatlán como el de Tantoyuca son considerados por Reyes Heroles con un cariz de comunismo agrario, Liberalismo, 1982, vol. III, pp. 569 y 574.

58 Reyes Heroles, Liberalismo, 1982, vol. III, pp. $570-571$. nuel Herrera, Juan Llorente y Cristóbal Andrade (prefecto de Huejutla) con el general Esteban Barbero, quien estaba secundando el Plan de San Luis, enarbolando las propuestas de Paredes y Arrillaga contra el gobierno nacional. En febrero y marzo se consideró la posibilidad de que los sublevados tuvieran negociaciones y comercio con los estadunidenses, ya que los de San Nicolás habían ofrecido ponerse bajo la protección de la bandera de Estados Unidos.59

Posiblemente esta alianza de los rebeldes con los estadunidenses estaba encaminada a considerar a los invasores como una alternativa viable para alcanzar los objetivos planteados, hecho que no implicaba una "traición" al país, ni una falta de "nacionalismo" hacia una "nación mexicana", inexistente o abstracta. La pregunta es hasta qué punto los rebeldes se sentían más identificados con sus pueblos que con un país llamado México. Creo que por la forma en que se desarrollaron los movimientos rurales huastecos, los pobladores rurales se sentían más identificados con sus pueblos que con un ente abstracto (México), ya que sus primeras reivindicaciones reflejaban más un sentimiento local que nacional. Además, el que los levantados no se movieran de la zona que conocían implicaba que los movimientos se lle-

59 "Carta del 20 de marzo de 1848 del prefecto de Huejutla", AHSDN, fondo Siglo XIX, exp. XI/ 481 .3/2772, fs. 50-51. En la Memoria del gobernador de Puebla de 1849 se consideraba que la "revolución expoliatoria, llamada de San Nicolás", tenía su origen en la ocupación del país por los estadunidenses. Memoria que sobre la ad. ministración, 1849, pp. 18-19. 
varan a cabo en lugares más localizados; esto es, los indígenas y no indios de Amatlán y San Nicolás, nunca traspasaron los límites de la jurisdicción política y geográfica por ellos conocida. ${ }^{60}$

Para mediados de 1848 el movimiento dejó de lado los intereses de la elite que lo había impulsado. La presencia de rebeldes en la sierra Huasteca y al sur de Amatlán permite pensar que el movimiento dejó de ser controlado por Llorente, Andrade y Herrera. Posiblemente los dirigentes habían conseguido las metas que se habían propuesto, por lo que los antes líderes se convirtieron en los represores. Así, surgieron nuevos dirigentes como Hilario Galván y Pedro Hernández; el primero concentró sus actividades en los llanos, mientras que el segundo se encontraba en la sierra. A partir de esta nueva dirigencia, el movimiento tuvo nuevas características. En una proclama de Galván, fechada el 5 de junio de 1848 , se mencionó que el asunto que defendian con las armas ya no era político, como lo había sido a principios de año, sino en contra de los hacendados, quienes en contubernio con las autoridades civiles y militares, explotaban y asesinaban a los campesinos. Galván denunció también la política represiva del ejército, de "tierra arrasada", esto es: la quema de las casas, de los pueblos y rancherías rebeldes, así como de las cosechas. ${ }^{61}$

${ }^{60}$ Michael Ducey considera que los campesinos de las Huastecas tuvieron en el fondo un espíritu nacionalista, ya que sus intereses se vieron afectados por la invasión extranjera. Véase Village, 1992, vol. II, p. 319.

61 "Proclama de Hilario Galván, general en
El gobierno central estaba en un dilema; por un lado, la rebelión del general Paredes y Arrillaga parecía tomar fuerza gracias a su alianza con los rebeldes de la Sierra Gorda en contra de los tratados de paz con Estados Unidos, y por otro, los rebeldes de las Huastecas pretendían unirse a los sublevados de la Sierra Gorda. El prefecto de Huejutla consideró que la unión de los rebeldes huastecos con los serranos traería como consecuencia una "revolución de castas que será difícil de contener y tan horrorosa como lo es el modo encarnecido con que ya se ha manifestado y ramificado por toda la república". ${ }^{62}$

Frente a estos hechos, se presentaba la escasez de hombres, para poder evitar la unión de los rebeldes. El general Arista, como ministro de Guerra, manifestó la imposibilidad de enviar tropas profesionales a la Huasteca, ya que era necesario derrotar a Paredes,

jefe de la Reunión Libertadora", AGN, Gobernación, caja 357, exp. 2, fs. 126-127. En julio de 1848 el prefecto de Ozuluama, Juan Manuel Maldonado, informó sobre la "quema" realizada por una partida del ejército en la zona rebelde, donde, además, se confiscaron caballos y se asesinaron indigenas que estaban solicitando el indulto. "Unión de los estados de México, Puebla y Veracruz para la pacificación de la Huasteca y nombramiento de comisionado de los mismos hechos en el Sr. Verdiguel", AGN, Gobernación, caja 357 , exp. 2, fs. 102-103. Un año después, los indigenas decían: "Cuando nuestros ojos se dirigen a las montañas que habitamos y lo vemos arrasado por el incendio, nuestros ojos se bañan de lágrimas." Véase "Representación que los vecinos de varios pueblos del estado de Veracruz hacen al Excmo Sr. Presidente de la República", AGN, Gobernación, caja 383, exp. 13, s/s.

62 "Carta del 26 de marzo de 1848 del prefecto de Huejutla", AHSDN, fondo Siglo XIX, exp. XI/ $481.3 / 2835$, f. 68 . 


\section{SECUENCIG}

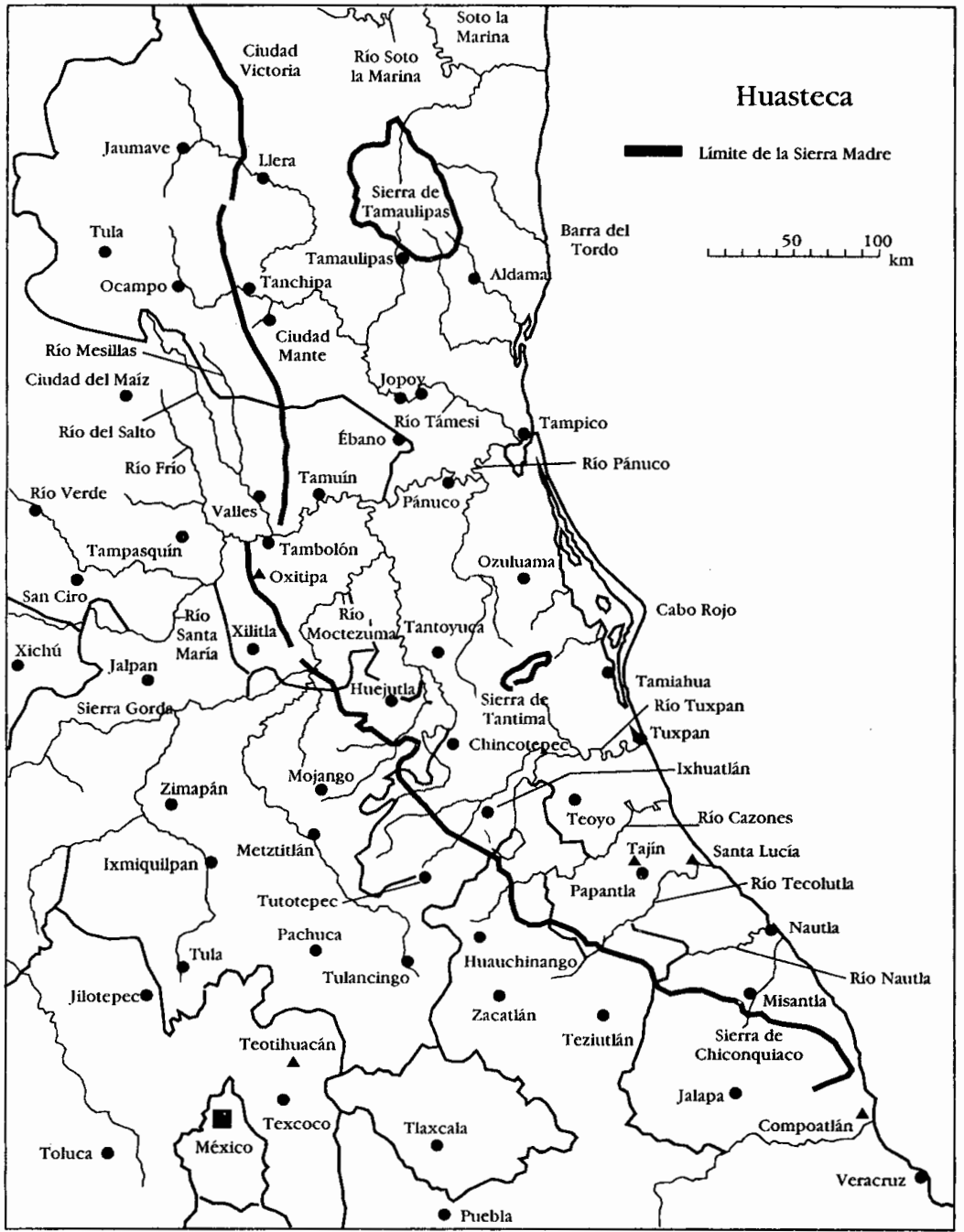

FuENTE: Mapa de la costa del Golfo de México, Guy Stresser-Péan, La Huasteca et la frontière Nord-est de la Mésoamérique, París, 1979. 
pero sugería que el gobernador del estado de México destacara milicias de Tulancingo a Huejutla, puesto que también existía la posibilidad de que esa población apoyara al movimiento de Paredes.

Con la derrota de Paredes por el general Anastasio Bustamante pudieron enviarse tropas a Huejutla. El aumento de las tropas significó la paulatina derrota numérica de los rebeldes, logrando así evitar su intento de unirse a Eleuterio Quiroz en la zona de la Huasteca potosina.

\section{CONSIDERACIONES FINAIES}

Como pudimos apreciar, en las rebeliones de Papantla y de las Huastecas existieron puntos comunes que sirvieron como detonantes. Las elecciones en los ayuntamientos y su control por sectores de la elite llevaron a una participación activa de los indígenas, tanto dentro de los movimientos como en la elección de los funcionarios municipales. El conflicto político nacional ocasionó también que los indios y no indios se vieran inmersos en ese tipo de luchas. No podemos dudar de que las reivindicaciones campesinas se hayan incrustado en las políticas como una primera fase, situación que posteriormente se pierde cuando las "masas" comienzan, probablemente, a perder el contacto con los líderes o cuando deciden retomar las quejas iniciales. Este tipo de conflicto político social puede ser observado como un conflicto faccional, en el sentido de que las facciones rurales son estructuralmente semejantes, es decir, representan simi- lares configuraciones de grupos sociales. En este caso, el modelo de facción propuesto por Alavi puede describir un conflicto segmental y no un conflicto de clase y etnia, esto es, que los conflictos en las Huastecas no llegaron a tener una expresión ideológica, porque las facciones rivales o los líderes lucharon por el control de los recursos, por el poder y el estatus tal como se presentaban dentro de la sociedad existente, y no por cambios en la estructura social. ${ }^{63}$

Los campesinos fueron los beneficiados al formar parte del "partido del desorden", para usar un término de Vanderwood. ${ }^{64} \mathrm{El}$ estado casi constante de guerra dio a los pueblos indios una gran oportunidad para armarse; los campesinos indígenas y no indios fueron movilizados para pelear contra los invasores extranjeros o con una u otra facción de la escena política nacional. La movilización resultó relativamente fácil, pero desarmar al campesinado se presentaba más dificil. El peso del campesinado armado bien puede explicar las frustraciones de los gobernantes en sus intentos de imponer un régimen de propiedad privada. La prudencia parece haber sido la característica más común en cuestiones referentes a la tenencia comunal de los pueblos. Hasta cierto punto, se ve un tipo de alianza entre políticos locales y el campesinado; es de recordarse que los movimientos más extensos contaron con la participación de políticos tales como Mariano Olarte

63 Véase Alavi, "Clases", 1976, pp. 44-125.

64 Vanderwood, Desorden, 1986, p. 49. 
en Papantla, Cristóbal Andrade en Huejutla, Juan N. Llorente en Chicontepec y Tantoyuca, y la familia Herrera en Chicontepec.

Podríamos considerar que la conformación de los ayuntamientos y su sobreposición en las estructuras político-territoriales de los pueblos indios trajo consigo una nueva conformación del espacio, tanto en la sociedad como en el pensamiento de los individuos. El nuevo órgano de poder local facilitó la emergencia de sectores socioeconómicos imposibilitados de participar en la arena política debido a la estructura colonial. Esta situación ocasionó diversos conflictos internos, ya que el control de la institución otorgaba una presencia al grupo poseedor de ese control, hecho que demeritó los diversos intentos de las elites huastecas por convertir un espacio histórico y geográfico en un estado, lo cual les hubiera permitido tener una mayor autonomía respecto del poder central controlado por otros sectores oligárquicos con tendencias más nacionales.

Las elites de las Huastecas no tuvieron ningún problema para llamar, en su lucha por el control político, a los campesinos, quienes de alguna manera intentaron incrustar en los movimientos suprarregionales sus propias reivindicaciones. Pero el intentar desarmarlos fue otra historia.

\section{BIBLIOGRAFÍA}

-Alavi, Hamza, "Las clases y las lealtades primordiales", Cuadernos Anagrama, núm. 128, 1976.

-Arrangoiz, Francisco de Paula, México desde 1808 hasta 1867, Porrúa, México, 1974 (Colección Sepan Cuántos).

-Benson, Nettie Lee, La diputación provincial y el federalismo mexicano, $\mathrm{El} \mathrm{CO}$ legio de México, México, 1952.

-Blázquez, Carmen (comp.), Estado de Veracruz. Informes desus gobernadores, 1826-1986, Gobierno del Estado de Vcrilcruz, Xalapa, 1986.

-Carmagnani, Marcello, "El federalismo liberal mexicano", en Marcello Carmagnani (coord.), Federalismoslatinoamericanos: México/Brasil/Argentina, Fondo de Cultura Económica/El Colegio de México/Fideicomiso Historia de las Américas, México, 1993.

-Colín, Mario, Guía de documentos impresos del estado de México (1824-1835), Biblioteca Enciclópedica del Estado de México, México, 1977.

-Corbett, Barbara M., "Las fibras del poder: la guerra contra Texas (1835-36) y la construcción de un Estado fisco-militar en San Luis Potosí", en Jorge Silva R. et al. (comp.), Circuitos mercantiles y mercados en Latinoamérica, siglos XVIII y XIX, UNAM/Instituto Mora, México, 1995.

-Chenaut, Victoria, Aquellos que vuelan. Los totonacos en el siglo XIX, CIESAS/ INI, México, 1995 (Historia de los pueblos indígenas de México).

-Chevalier, François, "La libertad muni. cipal, antigua y permanente reivindicación mexicana", Revista Mexicana de Sociología, año Ll, núm. 2, 1989.

-Chubb, Judith, Patronage, power and poverty in southern Italy, Cambridge University Press, 1982.

-Dublán, Manuel y José María Lozano, Legislación mexicana o colección de disposiciones legislativas expedidas desde la independencia de la República, Imprenta del Comercio, México, 1876.

-Ducey, Michael T., "From village riot to regional rebellion social protest in the Huasteca, México. 1760-1870", tesis Ph. D., 2 vols., Chicago, 1992. 
-Escobar O., Antonio, "La insurgencia huasteca: origen y desarrollo", en Jean Meyer (coord.), Tres levantamientos populares. Pugáchov, Tupac Amarú, Hidalgo, Clica, México, 1992.

"Los condueñazgos indigenas en las Huastecas hidalguense $y$ veracruzana: ¿defensa del espacio comunal?", en Antonio Escobar O. (coord.), Indio, nación y comunidad en el México del siglo XIX, CEMCA/CIESAS, México.

"De cabeceras a pueblos-sujetos. Las continuidades y transformaciones de los pueblos indios de las Huastecas hidalguense y veracruzana, 1750-1853", tesis de doctorado, El Colegio de México, México, 1994.

"Del gobierno indígena al Ayuntamiento constitucional en las Huastecas hidalguense y veracruzana, 1780 . 1853", en Mexican Studies/Estudios Mexicanos, vol. 12(1), 1996.

y Frans J. Schryer, "Las sociedades agrarias en el norte de Hidalgo, 1856-1900", Mexican Studies/Estudios Mexicanos, vol. 8, núm. 1, 1992.

-Estadística del estado libre y soberano de Veracruz. Comprende la memoria del gobierno presentada el 1 de enero de 1831, Imp. de Ignacio Cumplido, Jalapa, 1831.

-Exposición de las ventajas en que abunda la villa y puerto de Tuxpan para ser uno de los puertos abiertos al comercio de todas las naciones, s./e., México, 1836.

-Fages, Eduardo, "Noticias estadísticas sobre el departamento de Tuxpan", Boletín de la Sociedad Mexicana de Geografía y Estadística, núm. 4, 1a. época, 1854.

-Falcón, Romana, "Jefes políticos y rebeliones campesinas: uso y abuso del poder en el estado de México", en Jaime E. Rodríguez O. (comp.), Patterns of contention in mexican history; Delaware. A Scholary Resorces Inc. Imprint, University of California, 1992.
-Guedea, Virginia, "Las primeras elecciones populares en la ciudad de México, 1812-1813", Mexican Studies/Estudios Mexicanos, vol. 7, núm. 1, 1991.

-Hale, Charles, El liberalismo mexicano en la época de Mora, 1821-1853, Siglo Veintiuno Editores, México, 1978.

-Hamnett, Brian, "Factores regionales en la desintegración del régimen colonial en la Nueva España: el federalismo de 1823-1824", en Juge Busson, etal. (comp.), Problemas en la formación del Estado y la Nación en Hispanoamérica, Bohlan Verlag, Colonia y Viena, 1984.

-Legislación del estado de Veracruz desde el año de 1824, Imp. Veracruzana de Agustín Ruíz, Jalapa, 1881-1882.

-Lira, Andrés, Comunidades indigenas frente a la ciudad de México. Tenochtitlán y Tlatelolco, sus pueblos y barrios, 1812 1919, El Colegio de México/El Colegio de Michoacán/CONACyT, México, 1983. "Idea y realidad en la formación constitucional del municipio", en Brigitte Bohem (coord.), El municipio en México, El Colegio de Michoacán, México, 1987.

-Márquez, Enrique, "Tierra, clanes y política en la Huasteca potosina", Revista Mexicana de Sociología, año XIVIII, núm. 1, 1986.

-_ (comp.), San Luis Potosí. Textos de su historia, Instituto Mora, México, 1986.

-Meade, Joaquín, La Huasteca veracruzana, Editorial Citláltepetl, Jalapa, 1962.

-Memoria de las secretarias de Relaciones y Guerra, Justicia, Negocios Eclesiásticos e Instrucción Pública del gobierno del estado de México, leída a la honorable asamblea en las sesiones del día 1 y 2 de mayo de 1849, por el secretario de los ramos, Imprenta de J. Quijano, Toluca, 1849.

-Memoria que sobre la administración del estado de Puebla en 1849 bajo el gobierno del Excmo. Sr. D. Juan Mújicay 
Osorio, formada por el secretario del Despacho D. José M. Fernández Mantecón, y leída al $\mathrm{H}$. Congreso del mismo estado en las sesiones de los dias 1, 2, 3 de octubre de 1849, Imp. de Ignacio Cumplido, México, 1849.

-Pastor, Rodolfo, Campesinos y reformas: La Mixteca, 1700-1856, El Colegio de México, México, 1987.

-Pietschmann, Horst, "Protoliberalismo, reformas borbónicas y revolución: la Nueva España en el último tercio del siglo XVII", en Josefina Z. Vázquez (comp.), Interpretaciones del siglo XVIII mexicano. El impacto de las reformas borbónicas, Nueva Imagen, México, 1992.

-Reyes Heroles, Jesús, El liberalismo mexicano, Fondo de Cultura Económica, México, 1982.

-Rodríguez O., Jaime E., "La Constitución de 1824 y la formación del Estado mexicano", Historia Mexicana, vol. XL, núm. 3, 1991.

-Sierra, Justo, Evolución política del pueblo mexicano, UNAM, México, 1984.

-Sordo, Reynaldo, "Santa Anna y la República centralista de las Siete Leyes", en Alicia Hernández Ch. y Manuel Miño (coords.), Cincuenta años de historia en México, El Colegio de México, México, 1991.

Soto, Manuel F., El nuevo estado. La necesidad de formarlo inmediatamente con los cinco distritos de Tuxpan, Tampico de Veracruz, Tancanhuitz, Huejutla y el sur de Tamaulipas, Imprenta de Andrés Boix, México, 1855.
Noticias estadísticas de la Huasteca y una parte de la sierra alta, formada en el año de 1853, Imp. del Gobierno en Palacio, México, 1869.

-Téllez Guerrero, Francisco, "La segregación de Tuxpan y Chicontepec en 1853", en La Palabra y el Hombre, núm. 83, 1992.

-Thomson, Guy P.C., "Federalismo y cantonalismo en México, 1824-1892: soberania y territorialidad", en Anuario del IEHS, núm. 10, 1995.

-Van Young, Eric, "Haciendo historia regional: consideraciones metodológicas y teóricas", en Pedro Pérez Herrero (comp.), Región e historia en México 1700-1850, UAM/Instituto Mora, México, 1991.

-Vanderwood, Paul, Desorden y progreso. Bandidos, policíasy desarrollo económico, Siglo Veintiuno Editores, México, 1986.

-Vázquez, Josefina Z., "Dos décadas de desilusiones: en búsqueda de una fórmula adecuada de gobierno (1832-1851)", en Planes en la nación Mexicana, Senado de la República, México, t. II, 1987. "Un viejo tema: el federalismo y el centralismo", en Historia Mexicana, vol. XIII, núm. 3, 1993. "El federalismo mexicano, 1823-1847", en Marcello Carmagnani (coord.), Federalismoslatinoamericanos: México/Brasil/Argentina, Fondo de Cultura Económica/El Colegio de México/ Fideicomiso Historia de las Américas, México, 1993. 